\title{
A case of palmoplantar lichen planus
}

\section{Orhan Şen', Seray Külcü Çakmak', Emine Tamer1, Başak Yalçın', Ayşe Yılmaz Çiftçi²}

\author{
${ }^{1}$ Dermatology Clinic, Ankara Numune Education and Research Hospital, Ankara, Turkey, ${ }^{2}$ Pathology Clinic, Ankara Numune \\ Education and Research Hospital, Ankara, Turkey
}

Corresponding author: Dr. Orhan Şen, E-mail: eru2017@gmail.com

Sir,

Lichenplanus (LP) is an idiopathic, inflammatory skin disease which may occur in various location sand morphologies [1]. Palmoplantar lichen planus (PPLP) is an uncommon, localized variant of LP which shows atypical clinical features [2,3]. PPLP presents classically with pruritic, erythematous, scaly and/orhyperkeratotoic plaques with welldefinededges [3].

A 62-years-old female patient was admitted to our outpatient clinic with the complaint of a pruritic rash on her palmsandsoles for one year. The patients family and pastmedical history was not significant. Dermatological examination revealed multiple erythematous papules with scaling on the palmoplantar surfaces and dorsum of feet (Fig. 1). The oral and genital mucosas and nails of the patient were normal. The histopathological examination of the punch biopsy from the lesions revealed hyperkeratosis and acanthosis, thickening of granular layer, lichenoid infiltation in the dermoepidermal junction and few apopitotic keratinocytes in the epidermis which was consistent with LP (Fig. 2). Laboratory examinations including full blood count, routine biochemistry profile, hepatitis B and C serology were within normal limits, screening for human immunodeficiency virus infection and syphilis infection yielded negative results. The patient was diagnosed as PPLP and therapy with topical corticosteroid was started.

PPL is are rare form of LP which does not have the classically described clinical morphology of LP which makes the diagnosis difficult [4]. While typical LP is most common in women and between third and sixth decades, PPLP is more common in men between second and fifth decades $[2,5]$. The lesions commonly involve the internal plantar arch and thenar and hypothenar eminence of palms with out involvement of fingertips $[2,4]$. PPLP may have multiple clinical presentations. While the erythematous scaly form with or with out hyperkeratosis is the most common, vesicular, petechiea -like, umblicated, pigmented macular,and ulcerative forms may also be observed [3]. While PPLP may be presentonly on the palms and/ or soles, it may also be associated LP lesions on the other sites including mucosa land nail involvement in some patients [6].Our patient also had lesions on the dorsum of the hands. The histopathological features of PPLP is similar to classic LP. However parakeratosis, which is not a classical feature of classical LP has been described over half of the cases in a case series [7]. PPLP

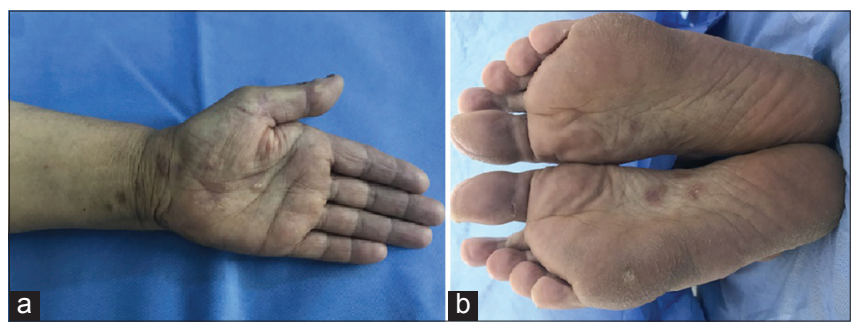

Figure 1: $(a$ and $b)$ Multiple erythematous papules with scaling on the palmoplantar surfaces.

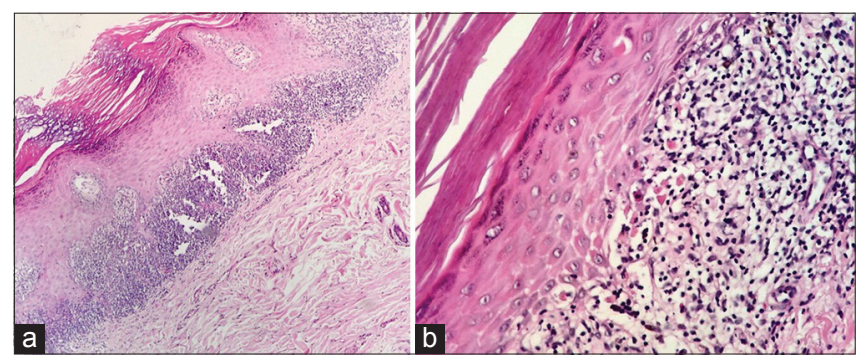

Figure 2: (a) Hyperkeratosis and acanthosis of epidermis, and distinct granular layer lichenoid infiltration in the dermoepidermal compartment (x10 H\&E). (b) Intraepidermal and basal apoptotic keratonocytes (Civatte Bodies) (x40H\&E).

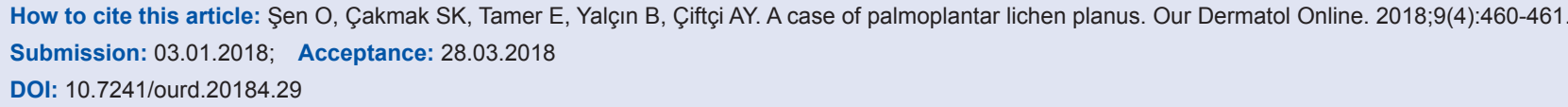


might be difficult to diagnose as it resembles many dermatoses that involvespalmoplantarareasincluding psoriasis,tineamanum/pedis, keratoderma, dyshidrotic eczema, mycosis fungoides, verruca vulgaris, and secondary syphilis $[2,3]$.The duration of the lesion sranges between 1 month and 8 years with the avarage of 11 months [6]. PPLP may be resistant to treatment and topical and intralesional corticosteroids, acitretin, tacrolimus, tazarotene, cyclosporine, methotrexate and dapson have been used with variable results in the treatment $[4,5,7]$.

Inconclusion we want to emphasize that PPLP is a rare form of LP and as it does not present with the classical, violaceous, flattopped papules the diagnosis may be challenging even for the dermatologists.

\section{Consent}

The examination of the patient was conducted according to the Declaration of Helsinki principles.

\section{REFERENCES}

1. Feily A, Yaghoobi R, Nilforoushzadeh MA. Treatment modalities of palmoplantar lichen planus: a brief review. Post Dermatol Alergol. 2016;33:411-5.

2. Kim YS, Kim MH, Kim CW, Shin DH, Choi JS, Kim KH. A case of palmoplantar lichen planus mimicking secondary syphilis. Ann Dermatol. 2009;21:429-31.

3. Abreu Velez AM, Howard MS, Pereyo N. Palmar and plantar lichen planus: a case report and review of the literature. An Bras Dermatol. 2015;90(3 Suppl 1):175-7.

4. Mehta V, Vasanth V, Balachandran C. Palmar involvement in lichen planus. Dermatol Online J. 2009;15:12.

5. Landis M, Bohyer C, Bahrami S, Brogan B. Palmoplantar lichen planus: A rare presentation of a common disease. J Dermatol Case Rep. 2008;2:8-10.

6. Gutte R, Khopkar U. Predominant palmoplantar lichen planus: a diagnostic challenge. Indian J Dermatol. 2014;59:343-7.

7. Kurmuş GI, Gönül M, Su AT, Gürçay N, Alper M. Palmar involvement in lichen planus. Our Dermatol Online. 2016;7:232-3.

Copyright by Orhan Şen, et al. This is an open-access article distributed under the terms of the Creative Commons Attribution License, which permits unrestricted use, distribution, and reproduction in any medium, provided the original author and source are credited.

Source of Support: Nil, Conflict of Interest: None declared. 